\title{
Estabilidade de agregados em argissolo sob diferentes usos, comparado com mata ${ }^{1}$
}

\author{
Arley Figueiredo Portugal ${ }^{2}$, Ivo Juncksh ${ }^{3}$, Carlos Ernesto R. G. Schaefer ${ }^{4}$, Julio César de Lima Neves ${ }^{3}$
}

\section{RESUMO}

A estrutura exerce grande importância no comportamento agrícola do solo, pela sua influência em propriedades do solo. Assim, objetivou-se avaliar a estabilidade de agregados e relacioná-la com diferentes frações orgânicas de um ARGISSOLO Vermelho-amarelo distrófico sob mata, seringueira, laranjeira e pastagem degradada. A amostragem foi realizada em trincheiras, de 0 a 10, 10 a 20 e 20 a $30 \mathrm{~cm}$. Foram analisadas textura, argila dispersa em água, grau de floculação, densidade do solo, carbono orgânico total (COT), nitrogênio total (NT), ácidos fúlvicos (AF), húmicos (AH) e humina (HN), carbono da biomassa microbiana (C-Micr) e matéria orgânica leve (MOL). Foi determinada a estabilidade de agregados em água e calculados índices de estabilidade. Os resultados mostram diferenças de densidade do solo, seguindo a ordem mata < seringueira < laranjeira < pastagem. A estabilidade de agregados não se altera entre os usos nas profundidades de 0 a 10 e 10 a $20 \mathrm{~cm}$, enquanto de 20 a $30 \mathrm{~cm}$ nota-se a ordem mata > seringueira > laranjeira $>$ pastagem. No solo sob mata, seringueira e laranjeria a estabilidade de agregados está relacionada aos maiores teores de COT, NT, AF, AH, HN, C-Micr e MOL, enquanto na pastagem está relacionada principalmente a ciclos de umedecimento e secagem.

Palavras-chave: Agregação, matéria orgânica, ciclos de umedecimento e secagem.

\section{ABSTRACT}

\section{Aggregate stability in an ultisol under different uses, compared with forest}

Soil structure has an important role in a soil's agricultural performance because of its influence on many soil properties. The objective of this work was to evaluate aggregate stability and relate it to different organic fractions of a red-yellow Ultisol under forest and cultivated with rubber trees, orange trees and under degraded pasture. Samplings were carried out in soil pits at the depths of 0-10, 10-20 and 20-30 cm. The following characteristics were analyzed: texture, water-dispersible clay, flocculation degree, soil density, total organic carbon (TOC), total nitrogen (TN), fulvic acids (FA), humic acids (HA), humin (HN), carbon in microbial biomass (C-Micr) and light organic matter (LMO). Water-stable aggregates and stability indexes were also calculated. Results showed differences in soil density but no differences in aggregate stability, at 0-10 and 10-20 cm both in the decreasing order: forest $<$ rubber plant $<$ orange $<$ pasture. At 20-30 cm, the aggregate stability was different, following the same order. In the soil under forest, rubber trees and orange trees, aggregate stability was related to higher TOC, TN, FA, HA, HN, C-Micr and LMO with lower C/ $\mathrm{N}$ ratio, whereas under pasture it was chiefly related to wetting and drying processes.

Key words: Organic Matter, soil aggregate, wetting-and-drying cycles.

\footnotetext{
Recebido para publicação em agosto de 2008 e aprovado em outubro de 2009

${ }^{1}$ Parte da Dissertação de mestrado do primeiro autor.

2 Engenheiro-Agrônomo, Doutor. EMBRAPA Milho e Sorgo, Caixa Postal 161, Zona Rural, 35701-970, Sete Lagoas, MG, Brasil, arley@cnpms.embrapa.br

${ }^{3}$ Engenheiros- Agrônomos, Doutores. Universidade Federal de Viçosa, Departamento de Solos, Av. Peter Henry Rolfs, s/n, 36570-000, Viçosa, MG, Brasil, ivo@ufv.br, julio_m2003@yahoo.com.br

${ }^{4}$ Engenheiro- Agrônomo, Ph. Doctor. Universidade Federal de Viçosa, Departamento de Solos, Av. Peter Henry Rolfs, s/n, 36570-000, Viçosa, MG, Brasil, carlos.schaefer@ufv.br
} 


\section{INTRODUÇÃO}

A estrutura apresenta grande importância no comportamento agrícola do solo, uma vez que exerce grande influência nos ciclos de carbono e de nutrientes, na capacidade de receber, estocar e transmitir água, na difusão de gases, na penetração das raízes e na capacidade de resistir à erosão, que são fatores importantes para o crescimento das plantas (Six et al., 2000; Portugal et al., 2008). Dessa forma, a estrutura do solo, geralmente avaliada pela distribuição e estabilidade dos agregados, tem sido proposta como um importante indicador da qualidade do solo (Six et al., 2000; Salton et al., 2008).

A teoria proposta por Tisdall \& Oades (1982) é a mais aceita para esclarecer como se formam os agregados do solo, sendo denominada de teoria da "hierarquização dos agregados”. Esses autores propõem uma classificação conforme o tamanho, sendo os agregados menores que $250 \mu \mathrm{m}$ denominados microagregados e, os maiores, macroagregados. Os mesmos autores observam que cada agregado é formado pela união dos agregados da classe que vem logo abaixo, seguindo, assim, uma ordenação hierárquica, sendo ainda cada classe de agregados unida por diferentes agentes de agregação.

Após a aproximação das partículas minerais, a matéria orgânica apresenta importante papel como um dos fatores determinantes da estabilização de agregados (Silva \& Mielniczuck, 1997; Six et al., 2000). Os compostos orgânicos participam das ligações entre partículas individuais do solo, atuando como agentes cimentantes das unidades estruturais pelas suas diversas características de superfície (Lima et al., 2003). Castro Filho et al. (1998) e Salton et al., (2008) indicam correlação direta entre conteúdo de matéria orgânica e estabilidade de agregados, enquanto Picollo \& Mbagwu (1990) e Bastos et al., (2005) enfatizam que são as frações da matéria orgânica ao invés da matéria orgânica total, que são mais importantes para a estabilidade estrutural.

Os polissacarídeos do solo são mucilagens provenientes do metabolismo microbiano e da decomposição de raízes, resíduos vegetais e animais e da exsudação radicular (Rangel et al., 2007). Tisdall \& Oades (1982) reportaram que os polissacarídeos atuam como agentes de ligação transitórios, sendo decompostos rapidamente pelos microrganismos e associados predominantemente a agregados $>250$ ìm, enquanto as substâncias húmicas associadas com ferro, alumínio e aluminossilicatos, são agentes de ligação persistentes de microagregados (<250 ìm). Picollo \& Mbagwu (1990) e Bastos et al. (2005) observaram a importância das substâncias húmicas na estabilidade dos agregados do solo, enquanto Gale et al. (2000) e Bronick \& Lal (2005) chamam a atenção para importância da matéria orgânica particulada e dos resíduos derivados das raízes na estabilização de macroagregados, enfatizando o potencial dos exsudados radiculares na formação e estabilização de macroagregados. Também a comunidade microbiana pode influenciar marcadamente a agregação do solo (Guggenberger et al., 1999; Dufranc et al., 2004; Bronick \& Lal, 2005).

Diversos são os fatores físicos que interferem na agregação do solo, incluindo-se também os ciclos de umedecimento e secagem como importante fator ambiental (Horn, 1990; Oliveira et al., 1996; Jantsch, 1997; Bertol et al., 2004; Bastos et al., 2005).

Sob o ponto de vista prático e de interesse econômico, o estudo das alterações na estrutura e agregação do solo, induzidas por seu uso do mesmo, assume importância relevante na previsão dessas alterações, com a finalidade de subsidiar a adoção de um sistema de manejo, que vise à manutenção ou recuperação do seu potencial agrícola e produtivo. Em condições tropicais existem poucos estudos sobre o estado de agregação de solos em diferentes tipos de usos agrícolas, bem como sua relação com as diferentes frações orgânicas do solo.

Neste sentido este trabalho teve o objetivo de avaliar a estabilidade de agregados e relacioná-la com as diferentes frações orgânicas de um Argissolo Vermelho-amarelo sob, seringueira, laranjeira e pastagem degradada, em relação à mata.

\section{MATERIAL E MÉTODOS}

O estudo foi realizado no município de Visconde do Rio Branco, na Zona da Mata do estado de Minas Gerais. A sede municipal situa-se nas coordenadas $21^{\circ} 00^{`} 40^{\prime \prime}$ de latitude sul e $42^{\circ} 50^{`} 20^{\prime \prime}$ de longitude W.Gr., e o município possui temperatura média anual de $23,9^{\circ} \mathrm{C}$, apresentando temperatura média máxima e mínima de 31,9 ${ }^{\circ} \mathrm{C}$ e $16{ }^{\circ} \mathrm{C}$, respectivamente. O índice pluviométrico anual no município é de $1100 \mathrm{~mm}$, com as chuvas concentradas no período de outubro a março (Sebrae, 2001), apresentando, de acordo com a classificação climática de Köppen, clima Cwa.

Foram separados os usos seringueira, laranjeira, pastagem degradada e mata, localizados na mesma posição na encosta, considerados como os tratamentos. Em todas as áreas ocorre Argissolo Vermelho-amarelo distrófico latossólico (Embrapa, 1999). Os solos com seringueira e pastagem se encontravam sob este uso há mais de 20 anos, enquanto os com laranjeira há 7 anos. Todos os ambientes tiveram histórico de uso continuado com canade-açúcar por aproximadamente 100 anos, que provocou a degradação severa do solo, devido às práticas de manejo adotadas, com uso de queimadas e sem a preocupação com práticas conservacionistas, provocando grandes perdas de solo por erosão laminar, chegando a ocasionar 
a exposição do horizonte B. A mata não sofreu alterações antrópicas durante o período de ocupação com a atividade canavieira, e embora não represente a vegetação original (Mata Atlântica), serve como referência. No solo sob mata ocorrem muitas raízes finas e muito finas até $10 \mathrm{~cm}$, e raízes médias e grossas (entre 1 e 2 cm de diâmetro) até 60 cm. Há abundância de canais biológicos e galerias de térmitas e formigas.

No ambiente com pastagem, tem-se o capim-gordura (Melinis minutiflora P. Beauv.), e observam-se níveis avançados de degradação, com muitas plantas espontâneas e considerável área de solo exposto (estimativa de $40 \%$ do solo exposto). Observou-se selamento superficial causado por erosão laminar nos primeiros $5 \mathrm{~cm}$, fraca atividade biológica e poucas raízes. A degradação está associada às feições do relevo e ao manejo inadequado da pastagem, como a utilização de pastoreio sem pousio, a falta de controle da lotação do pasto (superpastejo) e ocorrência de queimadas. Não se utiliza corretivos químicos nesse ambiente.

No ambiente com laranjeira (Citrus sinensis (L.) Osbeck) tem-se o menor número possível de intervenções mecânicas, mantendo-se resíduos vegetais em superfície. Na implantação, foi realizada a calagem somente na cova, a adição de 10 litros de esterco de curral colocados ao redor da planta, e de $400 \mathrm{~g}$ de superfosfato simples por cova. Não foram realizadas práticas de aração e gradagem na área, e utilizou-se o espaçamento de 7 x $4 \mathrm{~m}$. O controle de plantas espontâneas é feito utilizando herbicida de pósemergencia (glifosato) na linha do plantio (4 L/ha), e nas entrelinhas, utiliza-se roçadeira tratorizada, três vezes ao ano. A adubação do pomar é realizada mediante análises do solo, utilizando o calcário dolomítico, aplicado em julho e sem incorporação; superfosfato simples (250 g planta/ano, colocados de uma só vez); sulfato de amônio e cloreto de potássio (2 kg de 15-0-15 (N-P-K) planta/ano), aplicados em 3 vezes ao ano. Realiza-se a aplicação foliar de Ca, Mg, Zn, Mn e B, três vezes por ano. A produção é de 30 toneladas de laranja/ha/ano. Tem-se raízes finas abundantes até $5 \mathrm{~cm}$, comuns até $25 \mathrm{~cm}$ e raízes médias concentradas até $25 \mathrm{~cm}$, sendo raras abaixo desta profundidade.

No ambiente com seringueira (Hevea brasiliensis) não é realizada a correção e fertilização do solo, bem como não se tem o tráfego de máquinas ou práticas que revolvam o solo, podendo-se observar uma espessa camada de resíduos vegetais depositada sobre ele. No plantio foi utilizado termofosfato (400 g/cova) e torta de filtro de usina de cana-de-açúcar (5 L/cova). Foi realizada a calagem somente na cova. O espaçamento é de 8 x 2,5m (500 plantas/ha). Utilizam-se aproximadamente $300 \mathrm{~g}$ de fungicida ha/ano (Benlate, Bayleton e Cycosin). A produção é de 200 kg/ ha/mês de borracha. Há abundância de raízes pequenas e médias em todo o perfil, restos de folhas incorporadas até 10 cm, e abundância de canais biológicos de cupins, formigas e minhocas.

A amostragem foi realizada no mês de julho, em 2004. Em cada forma de uso (tratamento), e de modo aleatório, foram abertas seis trincheiras, consideradas como as repetições, nas quais foram feitas coletas nas profundidades de 0 a 10, 10 a 20 e 20 a $30 \mathrm{~cm}$. Coletaram-se amostras indeformadas para avaliar densidade do solo e estabilidade de agregados, e amostras deformadas para obtenção da TFSA.

As análises físicas de densidade do solo pelo anel volumétrico, análise textural, argila dispersa em água e grau de floculação foram realizadas conforme métodos descritos por Embrapa (1997).

Para a determinação da estabilidade e distribuição de agregados utilizaram-se amostras indeformadas. Adotouse a técnica descrita por Kemper \& Chepil (1965) que separa os agregados em função de seus diâmetros, usando um jogo de peneiras com malhas 2; 1; 0,5; 0,25 e 0,105 mm. Foram calculados os índices de agregação: diâmetro médio ponderado (DMP) e diâmetro médio geométrico (DMG), segundo Kemper \& Chepil (1965); o índice de estabilidade de agregados (IEA), segundo Perin et al. (2002), e a \% de agregados estáveis na classe $>2 \mathrm{~mm}$ (AGRE2), usando as seguintes equações:

$\mathrm{DMP}=\Sigma_{\mathrm{xi}} \mathrm{DM}_{\mathrm{i}}$

$\mathrm{DMG}=10^{\text {Exi log (DMi) }}$

IEA $=(($ Ps - wp0,105 - areia $) /($ Ps - areia $)) * 100 \quad$ (Eq.3);

AGRE2 $=x i>2 * 100$;

em que: xi é a proporção de agregados de cada classe em relação ao total; DMi é o diâmetro médio de cada classe de agregados (para classe $>2 \mathrm{~mm}$ considerou-se DMi como $3 \mathrm{~mm}$ ) ; Ps é a massa da amostra seca (g); wp0,105 é a massa dos agregados da classe $<0,105$; xi $>2$ é a proporção de agregados da classe > que $2 \mathrm{~mm}$. Também foram calculadas as proporções de macroagregados (MACR) e microagregados (MICRO), somando-se a \% de agregados retidos nas classes acima e abaixo de $250 \mu \mathrm{m}$, respectivamente (Tisdall \& Oades, 1982). Foi calculado o índice de sensibilidade, sugerido por Bolinder et al. (1999), segundo a expressão: Is = As/Ac, em que Is é o índice de sensibilidade; As é o valor do DMP do solo para cada uso agrícola, e Ac é o valor do DMP do solo sob mata.

O carbono orgânico total (COT) foi determinado utilizando-se o método descrito por Yeomans \& Bremner (1988), e o fracionamento das substâncias húmicas foi realizado segundo a técnica descrita por Swift (1996), obtendo as frações ácidos fúlvicos (FAF), ácidos húmicos (FAH) e huminas (FHN). O nitrogênio total (NT) foi determinado 
após digestão sulfúrica, e quantificado por destilação Kjeldahl. O carbono microbiano (C-Mic) foi determinado pelo método da irradiação-extração, conforme Islam \& Weil (1998). A matéria orgânica leve (MOL) foi determinada segundo Sohi et al. (2001).

$\mathrm{Na}$ análise dos dados, os usos do solo foram os tratamentos, e as seis trincheiras em cada forma de uso as repetições. Utilizou-se o delineamento inteiramente casualizado. Os efeitos dos tratamentos de uso do solo sobre as suas propriedades foram testados por meio de análise de variância. Analisaram-se os efeitos dos tratamentos em cada profundidade, separadamente. Quando as variáveis foram estatisticamente diferentes, as médias foram comparadas pelo teste de Tukey a $5 \%$ de probabilidade. Foi feita a análise de correlação de Pearson entre os índices de agregação e as demais características avaliadas.

\section{RESULTADOS E DISCUSSÃO}

Pela análise textural pode-se classificar os Argissolos como argilosos, com exceção da pastagem degradada de 0 a 10 e 20 a $30 \mathrm{~cm}$, onde o solo foi classificado como argiloarenoso e muito argiloso, respectivamente (Tabela 1). Notase que, na profundidade de 0 a $10 \mathrm{~cm}$, os teores de areia (grossa e fina) são maiores nos solos com laranjeira e pastagem, ao passo que o teor de argila é menor, o que indica que nestes usos os solos sofreram maior perda de argila por erosão, associada ou não à iluviação. Nas demais profundidades o teor de argila não se diferenciou. Boix-Fayos et al. (2001) verificaram que a fração argila se correlacionava positivamente com os índices de agregação do solo. Se- gundo Oades (1993), solos de textura argilosa são mais alterados com o umedecimento e secagem, sendo a formação de poros e outras zonas de fraqueza por processos biológicos muito importantes nestes solos.

A argila dispersa em água (ADA) e grau de floculação (GF) não mostraram diferenças significativas com os usos dados aos solos, de 0 a $10 \mathrm{~cm}$. De 10 a 20 e 20 a $30 \mathrm{~cm}$ observa-se menores valores de ADA e maiores GF para solos com laranjeira e pastagem, possivelmente em função da presença de horizonte B exposto à superfície por erosão devida ao uso anterior, indicando maiores processos erosivos nesses ambientes. O solo com seringueira mostrou comportamento inverso, mas isto não interferiu na sua agregação (Tabela 1).

Os valores de DS mostram a ordem mata < seringueira $<$ laranjeira < pastagem, evidenciando degradação física no solo da pastagem (Tabela 1). Os maiores valores de DS na pastagem podem estar relacionados com o menor teor de COT, ao pisoteio e ao pastejo seletivo e freqüente do gado (Portugal et al., 2008) bem como maior ocorrência e intensidade de ciclos de umedecimento e secagem, que provocam a expansão e contração do solo, produzindo microrrachadurras, que quebram os agregados e permitem o rearranjo das partículas, adensando o solo (Oliveira et al., 1996; Portugal et al., 2008).

Pelos índices de estabilidade de agregados pode-se notar que, na profundidade de 0 a $10 \mathrm{~cm}$, o diâmetro médio ponderado (DMP), diâmetro médio geométrico (DMG), porcentagem de agregados maior que $2 \mathrm{~mm}$ (AGRE2), macroagregados (MACR) e microagregados (MICR) não apresentaram diferenças significativas entre os diferen-

Tabela 1. Valores médios para areia grossa (AG), areia fina (AF), silte (SIL), argila (ARG), argila dispersa em água (ADA), grau de floculação (GF) e densidade do solo (DS), sob diferentes usos e profundidade

\begin{tabular}{|c|c|c|c|c|c|c|c|}
\hline \multirow{2}{*}{ USOS } & AG & $\mathbf{A F}$ & SIL & ARG & ADA & GF & D S \\
\hline & \multicolumn{4}{|c|}{ dag kg $^{-1}$} & \multicolumn{2}{|c|}{$\%$} & $\mathbf{T} \mathbf{g ~ m}^{-3}$ \\
\hline Mata & $29 \mathrm{ab}$ & $8 \mathrm{a}$ & $11 \mathrm{a}$ & 52 b & $19 \mathrm{a}$ & 63 a & 0,99 a \\
\hline Seringueira & $22 \mathrm{a}$ & 9 a & $16 \mathrm{~b}$ & 52 b & $23 \mathrm{a}$ & $56 \mathrm{a}$ & $1,14 \mathrm{ab}$ \\
\hline Laranjeira & $29 a b$ & $13 \mathrm{~b}$ & 9 a & $50 a b$ & $18 \mathrm{a}$ & $63 \mathrm{a}$ & 1,29 bc \\
\hline Pastagem & 32 b & $15 \mathrm{c}$ & $12 \mathrm{a}$ & $41 \mathrm{a}$ & $18 \mathrm{a}$ & $57 \mathrm{a}$ & $1,47 \mathrm{c}$ \\
\hline Mata & $25 \mathrm{~b}$ & 8 a & $14 \mathrm{bc}$ & $53 \mathrm{a}$ & $23 a b$ & $57 a$ & $1,23 a b$ \\
\hline Seringueira & $18 \mathrm{a}$ & $10 \mathrm{~b}$ & 17 c & 55 a & $25 \mathrm{~b}$ & $55 \mathrm{a}$ & 1,18 a \\
\hline Laranjeira & $27 \mathrm{~b}$ & $13 \mathrm{~b}$ & 7 a & 53 a & 9 a & $83 \mathrm{~b}$ & $1,34 \mathrm{ab}$ \\
\hline Pastagem & $25 \mathrm{~b}$ & $12 \mathrm{~b}$ & $11 \mathrm{ab}$ & $52 \mathrm{a}$ & $16 a b$ & 68 a & $1,37 \mathrm{~b}$ \\
\hline Mata & $23 \mathrm{~b}$ & $7 \mathrm{a}$ & $14 \mathrm{~b}$ & $56 \mathrm{a}$ & $24 \mathrm{~b}$ & 56 a & $1,24 \mathrm{a}$ \\
\hline Seringueira & $20 a b$ & $10 \mathrm{bc}$ & $16 \mathrm{~b}$ & $54 \mathrm{a}$ & $22 \mathrm{~b}$ & 59 a & $1,23 \mathrm{a}$ \\
\hline Laranjeira & $24 \mathrm{~b}$ & 12 c & $5 a$ & 59 a & $3 \mathrm{a}$ & $94 \mathrm{~b}$ & $1,35 \mathrm{~b}$ \\
\hline Pastagem & $18 \mathrm{a}$ & $9 \mathrm{ab}$ & $10 a b$ & $63 \mathrm{a}$ & $2 \mathrm{a}$ & $97 \mathrm{~b}$ & $1,40 \mathrm{~b}$ \\
\hline
\end{tabular}

Médias seguidas pela mesma letra dentro de cada profundidade, entre os diferentes usos, não diferem estatisticamente entre si pelo teste Tukey, a 5\% de probabilidade. 
tes usos (Tabela 2). Somente o índice de estabilidade de agregados (IEA) apresentou diferença entre os usos, sendo menor para solos com seringueira, possivelmente pela maior dimensão da classe de agregados $<0,105$ mm nesse solo. De 10 a $20 \mathrm{~cm}$ somente AGRE2 mostrou diferenças significativas, com maior e menor valores para solos com seringueira e laranjeira, respectivamente. A partir dessa profundidade houve uma tendência de ocorrerem valores menores de DMP, DMG e AGRE2 nos solos sob laranjeira e pastagem, sendo que de 20 a $30 \mathrm{~cm}$ os valores de DMP e AGRE2 foram estatisticamente menores nos solos com laranjeira e pastagem. Esse resultado provavelmente se deve a menor ocorrência de raízes de 20 a $30 \mathrm{~cm}$, bem como pelo menor teor de substâncias húmicas (AF, AH e $\mathrm{HN}$ ) nesta profundidade nos solos com laranjeira e pastagem, em relação à mata e seringueira. Pode-se notar que os índices DMP e AGRE2 foram mais sensíveis às alterações ocorridas com os usos, conforme observado também por Wendling et al. (2005).

$\mathrm{O}$ diâmetro médio ponderado (DMP) é um índice que traduz a estabilidade dos agregados de toda a amostra (Dufranc et al., 2004). O índice de sensibilidade (IS) avalia se os valores de DMP dos usos agrícolas do solo foram diferentes daqueles observados no solo de mata, sendo que valores acima da unidade representam incremento na agregação, e valores menores, redução na agregação. Observando o IS pode-se notar que, de 0 a $10 \mathrm{~cm}$, a resistência dos agregados do solo foi semelhante entre si com os diferentes usos (Figura 1). A partir 10 a $20 \mathrm{~cm}$ os solos começaram a se diferenciar, sendo que o solo sob seringueira mostrou IS 6\% maior que a unidade, ao passo que sob laranjeira e pastagem os solos tiveram IS 9 e 5 \% menores, respectivamente. Isso indica que houve melhor agregação na seringueira e menor na pastagem e laranjeira. Na profundidade de 20 a $30 \mathrm{~cm}$ as diferenças foram marcantes, com o solo sob seringueira mantendo-se próximo ao da mata (3\% menor), enquanto solos sob laranjeira e pastagem tiveram IS 25 \% menor. Observa-se que a estabilidade dos agregados não se alterou em superfície, enquanto que a partir da profundidade 10 a $20 \mathrm{~cm}$, mostrou valores semelhantes aos da mata quando sob seringueira e reduzidos quando sob laranjeira e pastagem, sendo essa diferença ampliada na profundidade de 20 a $30 \mathrm{~cm}$. Isso evidencia o efeito do uso do Argissolo na sua agregação em subsuperfície, mais do que em superfície, indicando que em superfície há fatores diferentes envolvidos na estabilidade de agregados dos usos avaliados, não permitindo diferenciá-los quanto a agregação, o que não ocorre em profundidade.

Um agregado de elevado diâmetro médio ponderado (DMP) nem sempre apresenta adequada distribuição de tamanho de poros no seu interior, o que implica em qualidade estrutural variável (Bertol et al., 2004). Isto pode ser visto na pastagem degradada, onde se observa uma forte degradação física, evidenciada pela elevada DS em superfície, ainda que apresentasse elevada estabilidade de agregados. Valores baixos e não significativos para os coeficientes de correlação entre os índices de estabilidade e a DS (Tabela 4) corroboram que elevada estabilidade de agregados não se traduz, necessariamente, em boa qualidade estrutural e ambiente físico favorável.

Tabela 2. Valores médios para diâmetro médio ponderado (DMP), diâmetro médio geométrico (DMG), índice de estabilidade de agregados (IEA), porcentagem de agregados > $2 \mathrm{~mm}$ (AGRE2), porcentagem de agregados $>250 \mathrm{~mm}$ (MACR), porcentagem de agregados $<250 \mathrm{~mm}$ (MICR), para diferentes usos do solo e profundidades

\begin{tabular}{|c|c|c|c|c|c|c|}
\hline \multirow{2}{*}{ USOS } & DMP & DMG & IEA & AGRE2 & MACR & MICR \\
\hline & \multicolumn{4}{|c|}{$\longrightarrow$ mm } & \multicolumn{2}{|c|}{$\%$} \\
\hline & & & 0 a $10 \mathrm{~cm}$ & & & \\
\hline Mata & $2,33 \mathrm{a}$ & $1,43 \mathrm{a}$ & $85,11 \mathrm{~b}$ & 74,43 a & 84,05 a & $15,95 a$ \\
\hline Seringueira & $2,31 \mathrm{a}$ & $1,27 \mathrm{a}$ & 78,20 a & $75,30 \mathrm{a}$ & 79,92 a & $20,08 a$ \\
\hline Laranja & $2,23 \mathrm{a}$ & $1,31 \mathrm{a}$ & $85,84 \mathrm{~b}$ & 68,51 a & 85,00 a & 16,40 a \\
\hline Pastagem & $2,30 \mathrm{a}$ & $1,38 \mathrm{a}$ & $86,15 \mathrm{~b}$ & 73,00 a & 84,52 a & $15,47 a$ \\
\hline Mata & $2,04 \mathrm{a}$ & $1,15 \mathrm{a}$ & $84,77 \mathrm{a}$ & $60,91 \mathrm{ab}$ & 82,32 a & 17,68 a \\
\hline Seringueira & $2,17 \mathrm{a}$ & $1,16 \mathrm{a}$ & $80,42 \mathrm{a}$ & $68,11 \mathrm{~b}$ & 79,55 a & 20,45 a \\
\hline Laranja & $1,85 \mathrm{a}$ & $1,02 \mathrm{a}$ & 83,88 a & $41,42 \mathrm{a}$ & 81,14 a & $18,86 a$ \\
\hline Pastagem & $1,95 \mathrm{a}$ & $1,05 \mathrm{a}$ & $82,42 a$ & $57,01 \mathrm{ab}$ & 79,99 a & $20,00 \mathrm{a}$ \\
\hline Mata & $2,10 \mathrm{~b}$ & $1,19 \mathrm{a}$ & 84,05 a & 63,96 c & 82,11 a & 17,40 a \\
\hline Seringueira & $2,06 \mathrm{~b}$ & $1,17 \mathrm{a}$ & 84,23 a & 60,64 bc & 82,60 a & $17,40 \mathrm{a}$ \\
\hline Laranja & $1,58 \mathrm{a}$ & $0,87 \mathrm{a}$ & 84,65 a & $38,92 \mathrm{ab}$ & 80,77 a & $19,22 a$ \\
\hline Pastagem & 1,59 a & $0,88 \mathrm{a}$ & 85,54 a & $37,84 \mathrm{a}$ & 79,67 a & $20,33 a$ \\
\hline
\end{tabular}

Médias seguidas pela mesma letra dentro de cada profundidade, entre os diferentes usos, não diferem estatisticamente entre si pelo teste Tukey, a 5\% de probabilidade. 


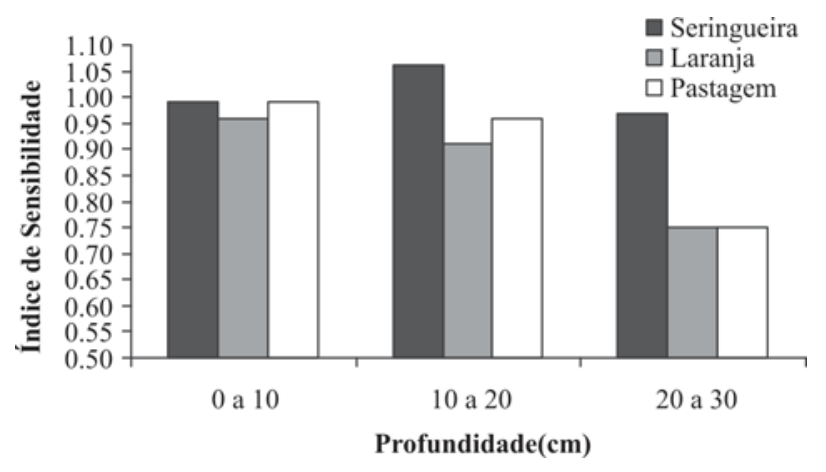

Figura 1. Índice de sensibilidade para diâmetro médio ponderado de agregados, em um Argissolo Vermelho-amarelo submetido a diferentes usos agrícolas, em relação à mata.

$\mathrm{O}$ fato dos ambientes não se diferenciarem quanto à estabilidade de agregados na profundidade de 0 a 10 e 10 a $20 \mathrm{~cm}$, indica que diferenças em carbono orgânico total (COT), nitrogênio total (NT), ácidos fúlvicos (AF), ácidos húmicos (AH), humina (HN), carbono da biomassa microbina (C-Micr) e matéria orgânica leve (MOL) não foram suficientes para explicar as diferenças de agregação em todos os ambientes, uma vez que estas características foram diferentes com os usos, sendo maiores para mata, seringueira e laranjeira, e sempre menores para pastagem (Tabela 3). Os maiores valores nos estoques de carbono e nitrogênio para mata, seringueira e laranjeira, se devem ao maior aporte vegetal nesses sistemas, tendo como conseqüência maior produção de resíduos vegetais, com presença maior de raízes e fauna do solo, além da maior proteção do solo contra impactos de gotas de chuva e menor ocorrência de ciclos de umedecimento e secagem. Os menores valores na pastagem são devidos ao nível avançado de degradação, com pouca cobertura vegetal, menor presença de raízes e fraca atividade biológica.

Nos solos de mata, seringueira e laranjeira, em superfície, a formação de macroagregados provavelmente está relacionada aos maiores valores das frações de matéria orgânica e nitrogênio, com conseqüente maior presença de polissacarídeos, fungos, raízes e atividade biológica, que são importantes agentes de formação dos macroagregados (Tisdall \& Oades, 1982). Gale et al. (2000) e Salton et al., (2008), afirmam que em sistemas com poucas perturbações, a formação e estabilização dos agregados são diretamente relacionadas com a decomposição de resíduos de raízes e a dinâmica da matéria orgânica leve (MOL), dependendo, portanto, de atividades biológicas. Segundo Bronick \& Lal (2005), a MOL pode agir como núcleo para formação de macroagregados pelo material acumulado ao redor, advindo da sua decomposição.

Na pastagem a agregação provavelmente está relacionada com a maior ocorrência de ciclos e umedecimento e secagem, devido à pouca cobertura do solo, ocasionando maior exposição aos raios solares. Como a camada super- ficial está sujeita a mais ciclos de umedecimento e secagem, e também mais intensos, estes podem ter contribuído para a maior estabilidade dos agregados nas profundidades de 0 a 10 e 10 a $20 \mathrm{~cm}$, já que qualquer agregado mais instável e dispersível é facilmente perdido por erosão neste sistema exposto, restando os agregados mais estáveis. A menor estabilidade de agregados de 20 a 30 cm corrobora a influência dos ciclos de umedecimento e secagem na agregação, uma vez que nessa profundidade a ocorrência e intensidade dos ciclos são menores, conforme também observado por Oliveira et al. (1996) trabalhando com ciclos de umedecimento e secagem.

Na pastagem, os agregados formados a partir das frações da matéria orgânica e atividade biológica, possivelmente se fragmentam quando submetidos aos ciclos de umedecimento de secagem (Jantsch, 1997; Bastos et al., 2005), provocando a exposição de cargas do interior dos agregados, que auxiliam em sua hidratação (Oliveira et al., 1996). Com a desidratação há um aumento progressivo da tensão na massa, até a ruptura em forma de fendas verticais e, ou, horizontais, a partir de pontos de fraqueza na superfície. Ao atingir a umidade de equilíbrio, as partículas se reorganizam, podendo ocorrer a formação de ligações estáveis entre os agregados (Bartoli et al., 1992).

Esses ciclos levam também à desidratação de ligantes orgânicos e inorgânicos do solo, que proporcionam a formação de agregados maiores e mais estáveis (Horn, 1990). A atração entre os agregados durante o processo de secagem pode ser explicada pelo surgimento de forças de atração relacionadas com o filme capilar entre as partículas. No material saturado, o espaço entre os agregados encontra-se completamente preenchido por água e a força de atração é zero. Com a perda de água, ocorre à formação do menisco com raio negativo, que causa o surgimento de uma força capilar de atração que fornece a energia para o deslocamento e a acomodação por deslizamento e translação dos agregados (Viana et al., 2004). Segundo Materechera et al. (1992), os ciclos de umedecimento e secagem influenciam na formação de agregados, e a cobertura vegetal influencia na magnitude, freqüência e efeito desses ciclos na agregação.

Avaliando-se todos os dados conjuntamente, nota-se que o DMP e AGRE2, que foram os índices de estabilidade mais sensíveis às mudanças de uso, apresentando correlações positivas com COT, NT, AH e HN, e negativas com DS (Tabela 4). Isso se deu possivelmente porque esses índices expressão melhor as alterações ocorridas na classe de agregados maior que $2 \mathrm{~mm}$, e não tanto as alterações na distribuição das classes de agregados. Esses resultados demonstram a importância do COT e substâncias húmicas mais humificadas (AH e HN) na agregação do solo. Picollo \& Mbagwu (1990) observaram que a estabilidade dos agregados do solo foi fortemente correlacionada com o conteúdo 
de substâncias húmicas. A fração AH apresentou as melhores correlações, indicando que este foi um importante agente de estabilidade de agregados, concordando com Bastos et al. (2005), que estudando a influência dos ciclos de umedecimento e secagem na formação e estabilização de agregados, mostraram que o AH foi o maior responsável pela estabilização dos agregados. Os mesmos autores concluíram que os ciclos de umedecimento e secagem reduziram os efeitos dos compostos orgânicos adicionados sobre a agregação do solo.

Neste estudo, a obtenção de coeficientes de correlação baixos, comparativamente à literatura, bem como a falta de correlação ou correlação negativa com variáveis sabidamente responsáveis pela agregação, ARG, GF, AF, $\mathrm{C}$-Micr e MOL, indicam que existem fatores diferentes atuando na agregação do solo nos diferentes usos. Em superfície, na seringueira e laranjeira, onde se tem boa produção de biomassa e entrada de carbono, a agregação provavelmente é devido aos maiores estoques de carbono, atividade biológica e presença de raízes em comparação com a pastagem degradada, onde o principal formador de agregados deve ser os ciclos de umedecimento e secagem, devido a baixa produção de biomassa e cobertura do solo. Já em subsuperfície, onde a ocorrência dos ciclos de umedecimento e secagem é menor, a pastagem degradada apresenta menor agregação, ao passo que a seringueira, onde se tem um ambiente com poucas perturbações, tem-se maior agregação do solo. Essas diferenças na agregação do solo entre os usos justifica as baixa correlações encontradas.

Tabela 3. Valores médios de carbono orgânico total (COT), nitrogênio total (NT), relação carbono/nitrogênio (C/N), carbono nas frações ácido fúlvico (AF), ácido húmico (AH) e humina (HN), carbono da biomassa microbiana (C-Micr) e matéria orgânica leve (MOL), para os diferentes usos do solo e profundidades

\begin{tabular}{|c|c|c|c|c|c|c|c|c|}
\hline \multirow{2}{*}{ USO } & COT & NT & $\mathbf{C} / \mathbf{N}$ & $\mathbf{A F}$ & АH & HN & \multirow{2}{*}{$\frac{\text { C-Micr }}{\mu \mathrm{g} \mathrm{g}^{-1}}$} & \multirow{2}{*}{$\frac{\text { MOL }}{\text { g kg-1 }^{-1}}$} \\
\hline & \multicolumn{2}{|c|}{ dag $\mathrm{kg}^{-1}$} & & \multicolumn{3}{|c|}{ dag $\mathrm{kg}^{-1}$} & & \\
\hline & & & & 0 a $10 \mathrm{~cm}$ & & & & \\
\hline Mata & $2,09 \mathrm{~b}$ & 0,19 c & $5,11 \mathrm{a}$ & $0,35 \mathrm{c}$ & $0,38 \mathrm{~b}$ & $1,34 \mathrm{~b}$ & $507,6 \mathrm{c}$ & $6,90 \mathrm{c}$ \\
\hline Seringueira & $1,81 \mathrm{ab}$ & $0,16 \mathrm{bc}$ & 6,60 a & $0,34 \mathrm{bc}$ & $0,29 \mathrm{ab}$ & $1,08 \mathrm{ab}$ & $351,1 \mathrm{~b}$ & $2,55 b$ \\
\hline Laranja & $1,64 \mathrm{ab}$ & $0,14 \mathrm{~b}$ & $7,05 \mathrm{a}$ & $0,26 \mathrm{~b}$ & $0,28 \mathrm{ab}$ & $1,07 \mathrm{ab}$ & $318,3 \mathrm{~b}$ & $1,94 \mathrm{ab}$ \\
\hline \multirow{2}{*}{ Pastagem } & $1,33 \mathrm{a}$ & $0,10 \mathrm{a}$ & $10,50 \mathrm{~b}$ & 0,17 a & $0,15 \mathrm{a}$ & 0,75 a & 156,5 a & $1,22 \mathrm{a}$ \\
\hline & & & & 10 a $20 \mathrm{~cm}$ & & & & \\
\hline Mata & $1,35 \mathrm{~b}$ & $0,14 \mathrm{~b}$ & 14,06 a & $0,29 \mathrm{~b}$ & $0,16 \mathrm{~b}$ & 0,97 c & 261,5 & $a b$ \\
\hline 3,30 & b & & & & & & & \\
\hline Seringueira & $1,32 \mathrm{~b}$ & $0,14 \mathrm{~b}$ & 14,56 a & $0,26 \mathrm{ab}$ & $0,14 \mathrm{ab}$ & $0,80 \mathrm{bc}$ & 328,1 b & $1,43 \mathrm{a}$ \\
\hline Laranja & $1,31 \mathrm{ab}$ & $0,11 \mathrm{ab}$ & $17,90 \mathrm{~b}$ & $0,24 \mathrm{ab}$ & $0,10 \mathrm{ab}$ & $0,75 \mathrm{ab}$ & 293,5 b & $0,65 \mathrm{a}$ \\
\hline \multirow[t]{2}{*}{ Pastagem } & $0,98 \mathrm{a}$ & $0,08 \mathrm{a}$ & 24,53 c & $0,20 \mathrm{a}$ & $0,04 \mathrm{a}$ & $0,58 \mathrm{a}$ & $130,4 \mathrm{a}$ & 0,83 a \\
\hline & & & & 20 a $30 \mathrm{~cm}$ & & & & \\
\hline Mata & 0,85 a & - & - & $0,31 \mathrm{~d}$ & $0,07 \mathrm{ab}$ & $0,76 \mathrm{~b}$ & - & - \\
\hline Seringueira & $1,19 \mathrm{a}$ & - & - & $0,26 \mathrm{c}$ & $0,13 \mathrm{~b}$ & $0,76 \mathrm{~b}$ & - & - \\
\hline Laranja & $1,01 \mathrm{a}$ & - & - & $0,21 \mathrm{~b}$ & $0,04 \mathrm{a}$ & $0,63 \mathrm{ab}$ & - & - \\
\hline Pastagem & 0,73 a & - & - & 0,15 a & $0,01 \mathrm{a}$ & $0,46 \mathrm{a}$ & - & - \\
\hline
\end{tabular}

Médias seguidas pela mesma letra dentro de cada profundidade, entre os diferentes usos, não diferem estatisticamente entre si pelo teste Tukey, a 5\% de probabilidade; - : não determinado.

Tabela 4. Coeficientes de correlação e a probabilidade entre os atributos: areia grossa (AG), areia fina (AF), silte (ST), argila (ARG), argila dispersa em água (ADA), grau de floculação (GF), carbono orgânico total (COT), nitrogênio total (NT), relação carbono/ nitrogênio (C/N), carbono nas frações ácido fúlvico (AF), ácido húmico (AH) e humina (HN), carbono da biomassa microbiana (CMic) e matéria orgânica leve (MOL), e os índices de estabilidade de agregados do solo: diâmetro médio ponderado (DMP) e geométrico (DMG), índice de estabilidade (IEA), porcentagem de agregados >2 mm (AGRE2), macroagregados (MACR) e microagregados (MICR), para diferentes usos do solo

\begin{tabular}{|c|c|c|c|c|c|c|c|c|c|c|c|c|c|c|}
\hline & IG & $\mathbf{F}$ & ST & ARG & IDA & GF & DS & $\mathrm{COT}$ & NT & $\mathbf{A F}$ & AH & HN & & \\
\hline & & & & & & & & & & & & & & \\
\hline & & & & & & & & & & & & & & \\
\hline & & & & & & & & & & & & & & \\
\hline & $02^{\mathrm{ns}}$ & & 18* & & & - & $-0,46^{*}$ & & & & & & & $0^{\mathrm{ns}}$ \\
\hline & & & & & & & & & & & & & & \\
\hline ICR &, $50 *$ & $-0,05^{\mathrm{ns}}$ & $0,22^{\mathrm{ns}}$ & $0,40^{\mathrm{ns}}$ & $0,09 \mathrm{~ns}$ & $0,04^{\mathrm{ns}}$ & $0,09^{\mathrm{ns}}$ & $-0,30^{\mathrm{ns}}$ & $-0,17^{\mathrm{ns}}$ & 0,07 ns & $-0,30^{\mathrm{ns}}$ & $-0,43^{*}$ & $-0,18^{\mathrm{ns}}$ & $-0,35^{\mathrm{ns}}$ \\
\hline
\end{tabular}

* significativo a $5 \%$ de probabilidade; ** significativo a $1 \%$ de probabilidade; ${ }^{\text {ns }}$ não significativo; 


\section{CONCLUSÕES}

Os diferentes usos do Argissolo mostraram diferentes graus de compactação, evidenciados pelos valores de densidade do solo, seguindo a ordem: mata $<$ seringueira $<$ laranjeira $<$ pastagem.

A estabilidade de agregados não se mostra diferenciada entre os usos na profundidade de 0 a $10 \mathrm{~cm}$ e 10 a 20 $\mathrm{cm}$, e entre 20 a $30 \mathrm{~cm}$, a estabilidade segue a ordem: mata $>$ seringueira $>$ laranjeira $>$ pastagem, evidenciando melhor os efeitos dos usos em subsuperfície.

No solo sob mata, seringueira e laranjeira a estabilidade de agregados está relacionada aos maiores teores de carbono orgânico total, nitrogênio total, ácidos fúlvicos, ácidos húmicos, humina, carbono microbiano e matéria orgânica leve, enquanto na pastagem degradada está principalmente relacionada a ciclos de umedecimento e secagem.

\section{REFERÊNCIAS BIBLIOGRÁFICAS}

Bartoli F, Burtin G \& Guérif J (1992) Influence of organic matter on aggregation in Oxisols rich in gibbsite or in goethite. II Clay disperson, aggregate strength and water-stability. Geoderma, 54:259-274.

Bastos RS, Mendonça ES, Alvarez VVH, Corrêa MM \& Costa LM (2005) Formação e estabilização de agregados do solo influenciados por ciclos de umedecimento e secagem após adição de compostos orgânicos com diferentes características hidrofóbicas. Revista Brasileira de Ciência do Solo, 29:21-31.

Bertol I, Alburquerque JA, Leite D, Amaral AJ \& Zoldan Junior WA (2004) Propriedades físicas do solo sob preparo convencional e semeadura direta em rotação e sucessão de culturas, comparadas às do campo nativo. Revista Brasileira de Ciência do Solo, 28:155-163.

Boix-Fayos C, Calvo A, Imeson AC \& Soriano-Soto MD (2001) Influence of soil properties on the aggregation of some Mediterranean soils and the use odd aggregate size and stability as land degradation indicators. Catena, 44:47-67.

Bolinder MA, Angers DA, Greegorich EG \& Carter MR (1999) The response of soil quality indicators to conservation management. Canadian Journal Soil Science, 79:37-45.

Bronick CJ \& Lal R (2005) Soil Structure and management: a review. Geoderma, 124:3-22.

Castro Filho C, Muzilli O \& Padanosch AL (1998) Estabilidade dos agregados e sua relação com o teor de carbono orgânico em um Latossolo Roxo Distrófico, em função de sistema de plantio, rotação de cultura e métodos de preparo das amostras. Revista Brasileira de Ciência do Solo, 22:527-538.

Dufranc G, Dechen SCF, Freitas SS \& Camargo AO (2004) Atributos físicos, químicos e biológicos relacionados com a estabilidade de agregados de dois Latossolos em plantio direto no estado de São Paulo. Revista Brasileira de Ciência do Solo, 28:505517.

Embrapa - Serviço Nacional de Levantamento e Conservação do Solo (1997). Manual de métodos de análise do solo. Rio de Janeiro, Ministério da Agricultura. 212p.

Gale WJ, Cambarella AC \& Bailey TB (2000) Root-derived carbon and formation and stabilization of aggregates. Soil Science Society of American Journal, 64:201-207.
Guggenberger G, Elliot ET, Fret SD, Six J \& Paustian K (1999) Microbial contributions to the aggregation of a cultivated grassland soil amended with starch. Soil Biology \& Biochemistry, 31:407-419.

Horn R (1990) Aggregate characterization as compared to soil bulk properties. Soil Tillage Research, 17:265-289.

Islam KR \& Weil RR (1998) Microwave irradiation of soil for routine measurement of microbial biomass carbon. Biology Fertility Soil, 27:408-416.

Jantsch RL (1997) Estado de agregação de materiais de Latossolos submetidos a calagem em diferentes condições de temperatura e umidade relativa. Dissertação de Mestrado. Universidade Federal de Viçosa, Viçosa, 78p.

Kemper WD \& Chepil WS (1965) Size distribution of aggregates. In: Black CA (ed) Methods of soil analysis. Part1. Madison, SSSA. p.495-509.

Lima CRL, Pauletto EA, Gomes AS \& Silva JB (2003) Estabilidade de agregados de um Planossolo sob diferentes sistemas de manejo. Revista Brasileira de Ciência do Solo, 27:199-205.

Materechera SA, Dexter AR \& Alston AM (1992) Formation of aggregate by plant roots in homogenised soils. Soil Plant, 142:69-79.

Oades JM (1993) The role of biology in the formation, stabilization and degradation of soil structure. Geoderma, 56:377-400.

Oliveira TS, Costa LM, Regazzi AJ \& Figueiredo MS (1996) Efeito de ciclos de umedecimento e secagem sobre a estabilidade de agregados em água de quatro Latossolos brasileiros. Revista Brasileira de Ciência do Solo, 20:509-515.

Perin A, Guera JGM, Texeira MG, Pereira MG, Fontana A (2002) Efeito da cobertura viva com leguminosas herbáceas perenes na agregação de um Argissolo. Revista Brasileira de Ciência do Solo, 26:713-720.

Picollo A \& Mbagwu JSC (1990) Effects of different organic waste amendments on soil microaggregate stability and molecular sizes of humic substances. Plant and Soil, 123:27-37.

Portugal AF, Costa ODV, Costa LM \& Santos BCM (2008) Atributos químicos e físicos de um Cambissolo Háplico Tb distrófico sob siferentes usos na zona da mata mineira. Revista Brasileira de Ciência do Solo. 32: 242-258.

Rangel OJP \& Silva CA (2007) Estoques de carbono e nitrogênio e frações orgânicas de Latossolo submetido a diferentes sistemas de uso e manejo. Revista Brasileira de Ciência do Solo, 31: 1609-1623.

Salton JC, Mielniczuk J, Bayer C, Boeni M, Conceição PC, Fabrício AC, Macedo MCM \& Broch DL (2008) Agregação e estabilidade de agregados do solo em sistemas agropecuários em mato grosso do sul. Revista Brasileira de Ciência do Solo, 32:11-21.

Sebrae - Diagnóstico da Fruticultura de Minas Gerais (2001) Minas Gerais, 202p.

Sohi S, Mahieu N, Arah JRM, Polwson DSP, Madari B \& Gaunt JL (2001) A procedure for isolating soil organic matter fractions suitable for modeling. Soil Science Society American Journal, 36:1121-1128.

Silva IF \& Mielniczuk J (1997) Avaliação do estado de agregação do solo afetado pelo uso agrícola. Revista Brasileira de Ciência do Solo, 21:313-319.

Six J, Paustrian K, Elliott ET \& Combrink C (2000) Soil Structure and organic matter: distribution of aggregate-size classes and aggregate-associated carbon. Soil Science Society American Journal, 64:681-689.

Swift RS (1996) Organic matter characterization. In: Methods of Soil Analysis. Part 3. Chemical Methods. DL Sparks (ed.). Madison, Soil Science Society American. p.1011-1069. 
Tisdall JM \& Oades JM (1982) Organic matter and water-stable aggregates in soils. Journal Soil Science, 33:141-163.

Viana JHM, Fernandes Filho Ei \& Schaefer CEGR (2004) Efeitos de ciclos de umedecimento e secagem na reorganização da estrutura microgranular de Latossolos. Revista Brasileira de Ciência do Solo, 28:11-19.
Wendling B, Jucksch I, Mendonça Es \& Neves JCL (2005) Carbono Orgânico e Estabilidade de Agregados de um Latossolo Vermelho sob Diferentes Manejos. Pesquisa Agropecuária Brasileira, 40:487-494.

Yeomans Jc \& Bremner JM (1988) A rapid and precise method or routine determination of organic carbon in soil. Communications in Soil Science and Plant Analysis, 19:1467-1476. 